\title{
Use of the Minimax Regret Approach for Robust Selection of Rainfall-Runoff Model Parameter Values Considering Multiple Events and Multiple Performance Indices
}

\author{
Chang Geun Song*, Eun-Sung Chung**, and Kwangjai Won***
}

\section{Erratum to: KSCE Journal of Civil Engineering (0000) 00(0):1-8 \\ DOI 10.1007/s12205-017-1972-0}

The original version of this article unfortunately contained a mistake.

Errata:

1.The title of the article was written incorrectly.

Use of the minimax regret approach for robust selection of rainfall-runoff model parameter values line break considering multiple events and multiple performance indices

Will be corrected as:

Use of the Minimax Regret Approach for Robust Selection of Rainfall-Runoff Model Parameter Values Considering Multiple Events and Multiple Performance Indices

The original article has been corrected.

*Member, Assistant Professor, Dept. of Safety Engineering, Incheon National University, Incheon 22012, Korea (E-mail: baybreeze119@inu.ac.kr)

**Member, Associate Professor, Dept. of Civil Engineering, Seoul National University of Science and Technology, Seoul 01811, Korea (Corresponding Author, E-mail: eschung@seoultech.ac.kr)

***Junior Engineer, Water Resources \& Environment Dept., Dongbu Engineering Co., Ltd, Seoul 01811, Korea (E-mail: babowkj@naver.com) 